\title{
PLANEAR A CIDADE COM AS PESSOAS
}

\section{PLAN THE CITY WITH THE PEOPLE}

\author{
Álvaro Fernandes \\ Câmara Municipal de Lisboa, Departamento de Planeamento (DP), Divisão de Reconversão das Áreas Urbanas de \\ Génese Ilegal (DRAUGI), Campo Grande, 15, 3. ${ }^{\circ}$ E, 1749-099 Lisboa, Portugal. \\ Email: alvaro.fernandes@cm-lisboa.pt
}

\begin{abstract}
Resumo: Os antigos “Bairros Clandestinos" de Lisboa tiveram o pico de construção nas décadas de 60 e 70. Foram o resultado de políticas urbanas e habitacionais inoperantes. Desde 2008, a Câmara Municipal de Lisboa (CML) promove a participação dos proprietários nos processos de reconversão através da organização de Comissões de Administração Conjunta, com o objetivo de gerir e reconverter as Áreas Urbanas de Génese Ilegal (AUGI). A intervenção nestes bairros tem contado com a participação de parceiros locais e residentes com o objetivo de promover um planeamento urbano participado (Friedman, 2011) e inclusivo. Este trabalho tem por base métodos participativos de intervenção tais como focus groups (Krueger \& Casey, 2000), mapeamento da comunidade (Pathways through Participation, 2010) efoto-vozes (Wang, 2006). Neste artigo pretende-se apresentar o processo em curso, da conceção do modelo de intervenção ao "modelo" de gestão da mudança social e urbana tendo como objetivo principal mitigar impactos sociais não desejados.
\end{abstract}

Palavras-chave: Áreas Urbanas de Génese Ilegal (AUGI), planeamento participado, focus groups, foto-vozes.

\begin{abstract}
Informal developers, bricklayers and unlicensed contractors have built, since 50s and 60s, "illegal districts"in Lisbon. Since 2008, Lisbon Municipality has circumscribed and controlled the growth of Urban Area of Illegal Origin (AUGI) based on a specific law. Landowners and landlords are now co-responsible to co-finance and manage all of the reconversion processes through their participation in Joined Administration Commissions with the Municipality. Participation of local partners and residents in a participated planning process (Friedman, 2011) is a key factor for a well-balanced urban planning to promote social inclusion. Participated methods like focus groups (Kruger \& Casey, 2000), community mapping (Pathways through Participation, 2010) and photo-voices (Wang, 2006) were used in this process. This paper presents a "work in progress", beginning with the development of an intervention methodology and ending on a methodology to manage social and urban change processes that aim to mitigate unintended social impacts.
\end{abstract}

Keywords: Urban Area of Illegal Origin (AUGI), participated planning, focus groups, photo-voices.

\section{Introdução}

Este trabalho pretende ser um documento reflexivo resultante de uma comunicação apresentada no Encontro da Associação Portuguesa de Sociologia, "Sociologia e Intervenção Local", que decorreu em Lisboa na Biblioteca de Marvila, em abril de 2017. Trata-se de uma reflexão a "quente" sobre um trabalho de intervenção ainda em curso nas 
Áreas Urbanas de Génese Ilegal do Concelho de Lisboa desenvolvido, nos últimos 2 anos, pela Divisão de Reconversão das Áreas Urbanas de Génese Ilegal (DRAUGI), estrutura recentemente criada no Departamento de Planeamento da CML. O referido trabalho de intervenção tem assumido um carácter integrado com vista à reconversão destas áreas urbanas, delimitadas formalmente desde 2008, e teve como principais fatores impulsionadores:

- A excecionalidade do contexto e do tipo de intervenção em curso;

- As evidências da mudança das "lógicas" sócio urbanas nas Áreas Urbanas de Génese Ilegal (AUGI) que poderão ter semelhanças em muitos outros concelhos sobretudo das áreas metropolitanas.

Esta reflexão não é um trabalho depurado ou decantado de análise social resultante de um processo de investigação. É, antes de mais, uma peça "orgânica" resultante de uma prática profissional e social gerida a partir de uma autarquia e fundamentada, sobretudo, em princípios e práticas da "sociologia de ação" (Guerra, 2006).

Assim, o trabalho que agora se apresenta segue o desenvolvimento cronológico de um projeto de trabalho com cerca de dois anos. Na primeira parte desta reflexão apresenta-se um enquadramento institucional, legal e histórico, sobre a evolução recente das Áreas Urbanas e Génese Ilegal, no fundo, a génese do fenómeno. A segunda parte relata a experiência de gestão da mudança a nível social desde a fase de ensaio de metodologias de intervenção até à sua fundamentação e posterior aplicação, em diferentes momentos e contextos urbanos, tendo sempre como objetivo a participação das pessoas. No último ponto, reflexões finais, problematizam-se alguns dos aspetos essenciais resultantes deste trabalho de terreno e coloca-se a hipótese das lógicas compreendidas serem idênticas noutras Áreas Urbanas de Génese Ilegal.

\section{A génese do fenómeno urbano}

\section{Apontamento sobre a história das AUGI}

Numa operação urbanística podemos identificar três grandes operações: o parcelamento, a urbanização e a edificação. No caso das Áreas Urbanas de Génese Ilegal do Concelho de Lisboa a ilegalidade abrange, pelo menos, uma destas operações e, em muito casos, envolveu todas elas. O fenómeno das Áreas Urbanas de Génese Ilegal não é um fenómeno exclusivo de Portugal. No Sul da Europa, por motivos históricos e culturais mas, sobretudo, devido aos modelos de desenvolvimento económico e social e também devido às políticas habitacionais promovidas após a II Guerra, 


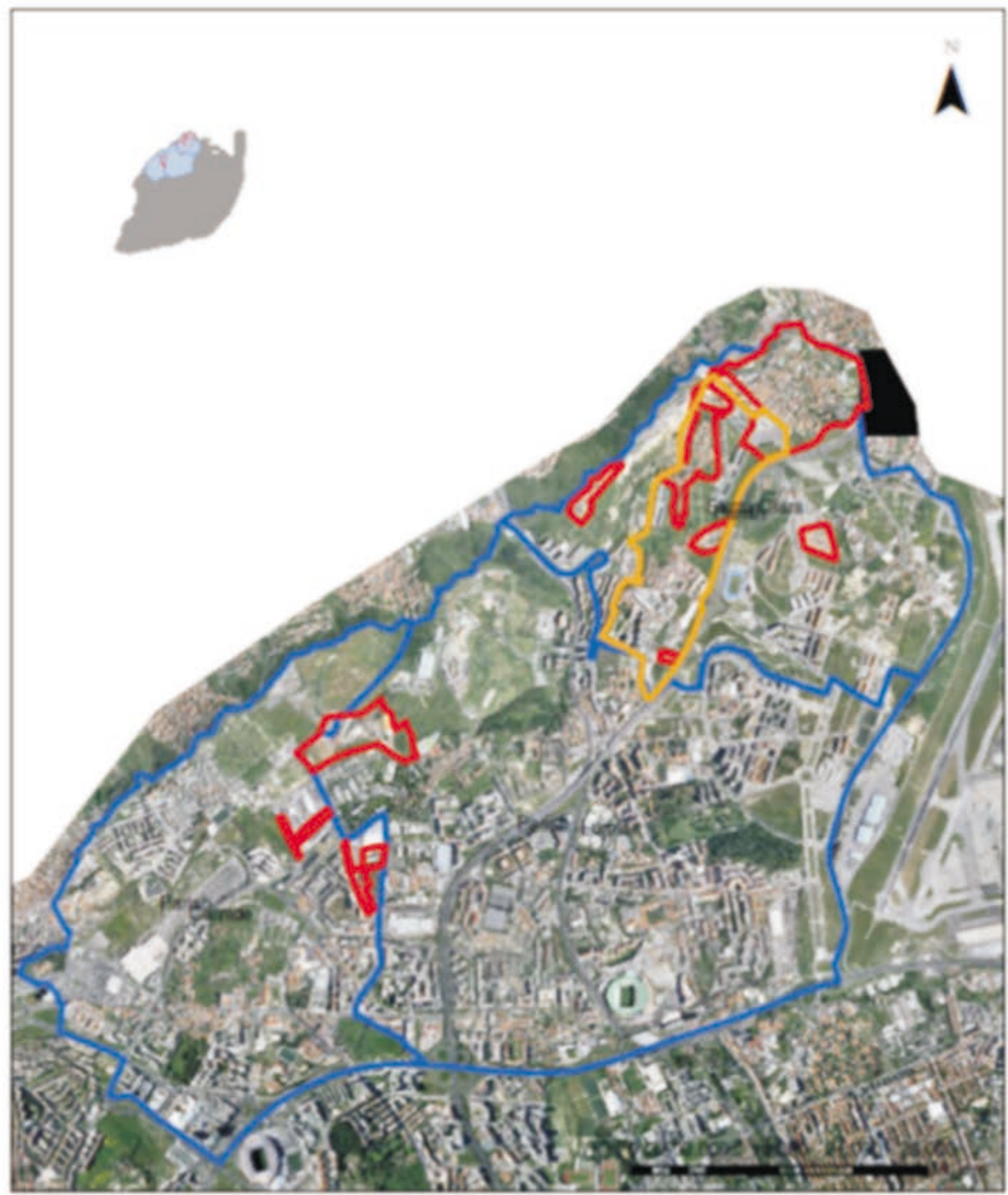

\begin{tabular}{|c|c|c|}
\hline & AREA & Fesidents 2011 \\
\hline Ounta ob Cratani & $18962 \mathrm{~m} 2$ & 2288 \\
\hline Alo do Chace ieve & $29013 m 2$ & 178 \\
\hline Bamo dos Sele Clus & $28337 \mathrm{~m} 2$ & 151 \\
\hline Rus particular a Az. dos Lameiros & $10514 m 2$ & 212 \\
\hline Ounta da Mourivea & $22007-2$ & 239 \\
\hline Galinheras & $377204 \mathrm{~m} 2$ & 3225 \\
\hline Ouints on Onval Casal dos Abestws & $131205 \mathrm{~m} 2$ & 40 \\
\hline Quanta de Torrinha & $94387 \mathrm{m2}$ & $7 \infty$ \\
\hline Plua A s Rua B a Az. Tome do Falo & $31202 \mathrm{~m} 2$ & 175 \\
\hline Plua Partecular a Azinhaga de Cidade & $4802 \mathrm{~m} 2$ & 25 \\
\hline
\end{tabular}

Lima ARU St+ Coust

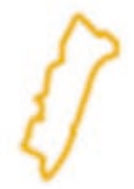

Figura 1 Mapa de localização das AUGI em Lisboa

Fonte: Câmara Municipal de Lisboa (2016a). 
criou-se um "sector informal" (UNECE \& FIG, 2015) de loteamento, venda de propriedades e construção de imóveis totalmente à margem da lei (Zanfi, 2013).

Os antigos bairros clandestinos em Portugal tiveram origem nos anos 60 e 70 e resultaram de diversos fatores económicos, sociais e culturais como refere Ferreira et al. (1985) no artigo "Perfil social e estratégias dos clandestinos? Destacamos alguns dos principais fatores identificados pelo autor:

Económicos - baixos rendimentos e salários de uma população de origem rural a instalar-se em meio urbano; escassez de habitação e especulação fundiária;

Institucionais - centralização, burocratização e rigidez do planeamento e gestão urbanística;

Culturais - aspiração de posse de casa própria com "quintal e horta" baseado nos sistemas de entreajuda das comunidades rurais e laços de família alargada para a construção. (Ferreira et al., 1985, p. 7)

Esta evolução não é obviamente linear e uniforme em todos os territórios. Há autores que assinalam uma segunda vaga de clandestinos nos anos 70 e 80 como sendo "clandestinos de lazer" situados próximos das praias e que têm especial incidência na Margem Sul do Tejo (Gonçalves et al., 2010, p. 45). O que se trata nos territórios em análise é de "clandestinos de primeira vaga" (Gonçalves et al., 2010, p. 46) casas que foram construídas para habitar e viver em permanência.

Assim, os bairros em análise no presente artigo situam-se todos na Coroa Norte da cidade de Lisboa, abrangendo as atuais Freguesias de Carnide, Lumiar e, muito especialmente, pelo volume e complexidade, a Freguesia de Santa Clara. Na figura 1, apresenta-se a localização das zonas delimitadas com as respetivas dimensões em área e em população com base nos Censos de 2011.

\section{A intervenção da CML nas AUGI}

A Câmara Municipal de Lisboa tem, desde 2008, desenvolvido um trabalho de reconversão das AUGI, com base na Lei n. ${ }^{\circ}$ 91/95, de 2 setembro, que vem reposicionar a intervenção das autarquias, apostando num modelo de gestão participada para os processos de legalização e reconversão. Este diploma reforça a participação dos proprietários sem enjeitar uma intervenção ativa da autarquia.

A partir desta data houve um esforço para impulsionar a criação de Comissões de Administração Conjunta cujas principais funções são, segundo o mesmo diploma, art. ${ }^{\circ}$ 15: " praticar os atos necessários ao processo de reconversão; acompanhamento técnico dos projetos e das obras de urbanização e sua execução e gestão dos respetivos orçamentos". 
As referidas comissões são de tipo associativo e têm os seguintes órgãos: assembleia de proprietários ou comproprietários, comissão de administração e comissão de fiscalização. Segundo o Artigo 9. ${ }^{\circ}$ da referida lei, o representante da câmara municipal deve, durante o funcionamento da administração conjunta, procurar fornecer os esclarecimentos necessários e úteis.

Em 2013, a autarquia publicou o Regulamento Municipal de Reconversão Urbanística de 2013 através do qual regula os procedimentos, com base na legislação em vigor, e define um conjunto de instrumentos de intervenção, nomeadamente "operação de loteamento de iniciativa dos particulares, operação de loteamento de iniciativa municipal, planos de pormenor, com ou sem o apoio da administração conjunta" (Câmara Municipal de Lisboa, 2013, art. $^{\circ}$ 4. $^{\circ}$ ).

No mesmo ano foi reconhecida a dimensão de intervenção social nas AUGI através da criação de um Gabinete para a gestão dos Bairros e Zonas de Intervenção Prioritária (BIP/ZIP), ${ }^{1}$ GABIP, dado que boa parte do trabalho implicava efetivamente intervenção social local.

Houve, assim, um reforço do trabalho de acompanhamento e articulação ao nível de instâncias e parceiros locais, nomeadamente Grupos Comunitários e Comissões Sociais de Freguesia no âmbito da Rede Social. Em 2015 foi criada uma equipa multidisciplinar e uma divisão própria na estrutura municipal, a DRAUGI, no Departamento de Planeamento.

\section{Gerir a mudança social no processo de reconversão urbana}

O processo de reconversão implica a gestão de processos de mudança socio-urbana longos e complexos. O processo de gestão urbanística, em si, implica, grosso modo, as seguintes fases: reconfiguração fundiária e reformulação total ou parcial do desenho urbano com implicações no espaço público, parcelas privadas e infraestruturas urbanas, que vão dos passeios aos sistemas de águas pluviais e às redes de abastecimento.

Prevê-se nos processos de reconversão urbanística em curso, nos núcleos urbanos delimitados como AUGI, a demolição de alguns imóveis dado que não apresentam critérios mínimos de conformidade com o RJUE, Regime Jurídico da Urbanização e Edificação, bem como, com os novos traçados urbanos em elaboração.

Com o objetivo de antever e prevenir os impactos negativos nesta fase da reconversão das AUGI houve necessidade de pensar em estratégias e modelos de intervenção que permitissem gerir, a par das alterações urbanísticas, as mudanças sociais daí decorrentes. 


\section{Ensaio da metodologia de intervenção}

Numa primeira fase, definiu-se como objetivo conceber um modelo de intervenção que ajudasse a antever e programar um enquadramento, com os "instrumentos adequados" de apoio à gestão do processo de intervenção naquele tecido urbano e assim mitigar impactos sociais não desejados e minimizar todos os fatores desestabilizadores dos residentes em situação social mais vulnerável.

Em simultâneo, pretendeu-se definir um quadro de gestão de informação que esclareça moradores e interessados sobre todo o processo e que promova, igualmente, a redução de fenómenos como o rumor ou o boato naturalmente associados a este tipo de intervenção.

Face à definição destes objetivos verificou-se que seria importante proceder ao ensaio de uma metodologia de intervenção. Foi escolhida uma das AUGI, a Quinta do Olival e Casal dos Abrantes.

A escolha desta zona assentou em critérios claros, tais como: a pequena dimensão da AUGI; a existência de uma Comissão de Administração Conjunta constituída; o facto de se tratar de um "microcosmos" relativamente isolado face ao tecido urbano próximo; o facto de haver um processo de dinamização dos moradores desenvolvido pela Junta de Freguesia local através de projetos de intervenção apoiados no âmbito do Programa BIP/ZIP.

Foi constituída uma equipa de 3 técnicos: 1 Técnico de Intervenção Social e 2 de Arquitetura e Urbanismo que realizou, entre novembro de 2015 e fevereiro de 2016, visitas a 32 imóveis habitacionais correspondentes a um total de 79 frações, 7 edifícios totalmente devolutos, 2 de função habitacional e 5 não habitacional, e ainda, 4 edifícios que alojam empresas em laboração. Estas visitas técnicas foram efetuadas aos imóveis que, no âmbito da elaboração do Plano de Pormenor do Quinta do Olival, se prevê virem a ser demolidos.

Uma análise comparativa dos Censos 2001 e 2011 e, posteriormente, a sua confrontação com os dados recolhidos durante as visitas técnicas, permitiu-nos chegar a uma primeira conclusão importante patente na figura 2.

A partir de 2001 o Bairro perdeu a quase totalidade de "proprietários residentes" a par de um aumento significativo das habitações vagas.

Podemos dizer que a Quinta do Olival e Casal dos Abrantes é um microcosmos em transformação. Inicialmente, nos anos 60 e 70, era constituído por migrantes internos oriundos das zonas rurais do país, originários da mesma zona e até do mesmo Concelho e Vila: Pombal - Abiul.

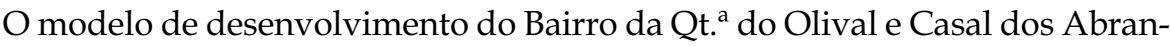
tes baseou-se na construção inicial de "Vivendas" de forma faseada e conforme a 


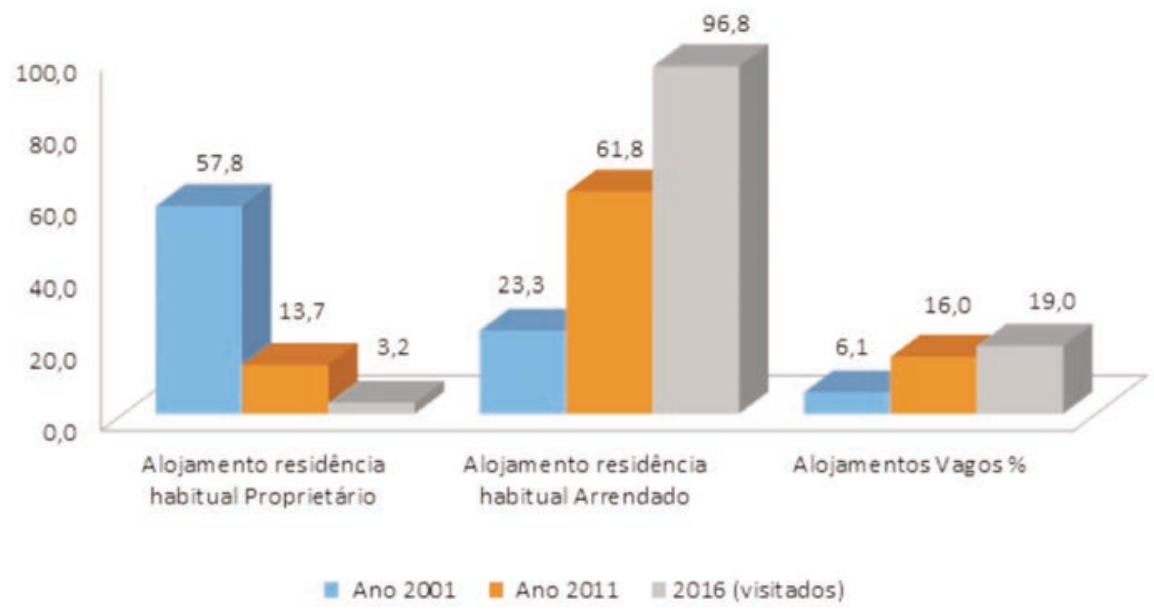

Figura 2 Evolução da ocupação dos alojamentos 2001e 2011 Censos; 2016 (amostra alojamentos visitados (\%) Fonte: Câmara Municipal de Lisboa (2016a).

disponibilidade de tempo e dinheiro das famílias. Posteriormente foram construídos anexos cuja função era alojar familiares e conterrâneos mas, sobretudo, foram concebidos como fonte de rendimento complementar após a reforma dos proprietários.

Concluiu-se, do processo de levantamento e das visitas, que esta AUGI se encontra num processo de mudança mais profunda, salientando-se:

1. Os fogos não têm sido ocupados pelos herdeiros dos "construtores";

2. Os imóveis são fonte de rendimento para explorar até que algo "realmente aconteça" no processo de reconversão;

3. Alguns dos fogos, mesmo sem condições de habitabilidade, têm servido, mediante apoio económico das instituições, como recurso para a resolução temporária de situações de emergência social;

4. A oferta de habitação barata para situações transitórias e precárias em termos laborais ou familiares, para deslocadas em comissão de serviço, em situação de insolvência, entrega de casa aos bancos, divórcio, etc.;

5. Instalação de empresas de serviços de baixo valor, zona acessível e barata;

6. Permanecem os antigos arrendatários que não têm outras alternativas: "casa na terra"; capacidade económica; rede familiar, etc.;

7. Zona em processo de "desqualificação" social. 
Definição de metodologia de abordagem para as AUGI

Tendo em conta os objetivos da organização e dos processos a implementar, a reconversão urbana das AUGI, com uma delimitação já definida e com um quadro legal próprio, havia que abordar as AUGI, enquanto objeto de estudo e campo de intervenção. Isto trouxe o desafio de se equacionar um referencial válido e "partilhável" do ponto de vista multidisciplinar e temporal.

Como base essencial socorremo-nos da Sociologia da ação na perspetiva de Isabel Carvalho Guerra que defende uma perspetiva menos abstrata e mais concreta e, sobretudo, indutiva (Guerra, 2006, p. 51) em relação ao processo de análise sociológica. Além deste facto, a prática profissional dos profissionais das ciências sociais trás consigo também uma dimensão institucional/organizacional que formata, determina, constrange o seu campo de ação (Guerra, 2006, p. 183). Houve assim, a necessidade de "definição de um modelo" (Guerra, 2006, pp. 88-89) que correspondesse a um campo de intervenção e a "hipóteses" para o desenvolvimento e gestão cronológica muito fundamentada na metodologia da Investigação-Ação e Gestão de Projeto (Guerra, 2006, p. 107). Nesta abordagem acabaram por convergir perspetivas já tradicionais da Intervenção Comunitária e Desenvolvimento Local (Pane, 2002, p. 120) assentes em parcerias que promovem uma ligação mais direta aos clientes/ utentes e organizações locais (Pane, 2002, p. 121). Esta abordagem encontra-se atualmente instituída na Rede Social de Lisboa. Foi aqui também convocada a abordagem sistémica do Serviço Social (Pane, 2002, p. 122) que promove o trabalho em rede entre instituições e organizações locais e insere-se numa lógica de tornar mais eficazes, integradas e adequadas as respostas socias e as Politicas Sociais às necessidades e aos problemas.

Por último, mas não menos importante, o planeamento urbano como "motor" fundamental de todos estes processos de reconversão urbana tem vindo a tornar-se mais permeável a novas abordagens. Trata-se de experiências na Área do Planeamento Urbano e do Urbanismo (Horelli et al., 2013) onde os atores e as relações sociais que "fazem" e constituem a cidade subvertem as tradicionais abordagens, de cima para baixo, centradas meramente na parte visível do desenho urbano do edificado, ao espaço público. Houve assim, que equacionar em todo o processo os elementos comuns e transversais a estas tradições e abordagens disciplinares: todos eles visam promover e/ou gerir processos de mudança (Friedman, 2011): a partir de um contexto institucional (autarquia local) organizacional e profissional; onde se apresentam também vários atores com interesses diversos, proprietários, moradores, organizações locais que, de forma direta ou indireta, mais ou menos ativa, participam nestes processos. 


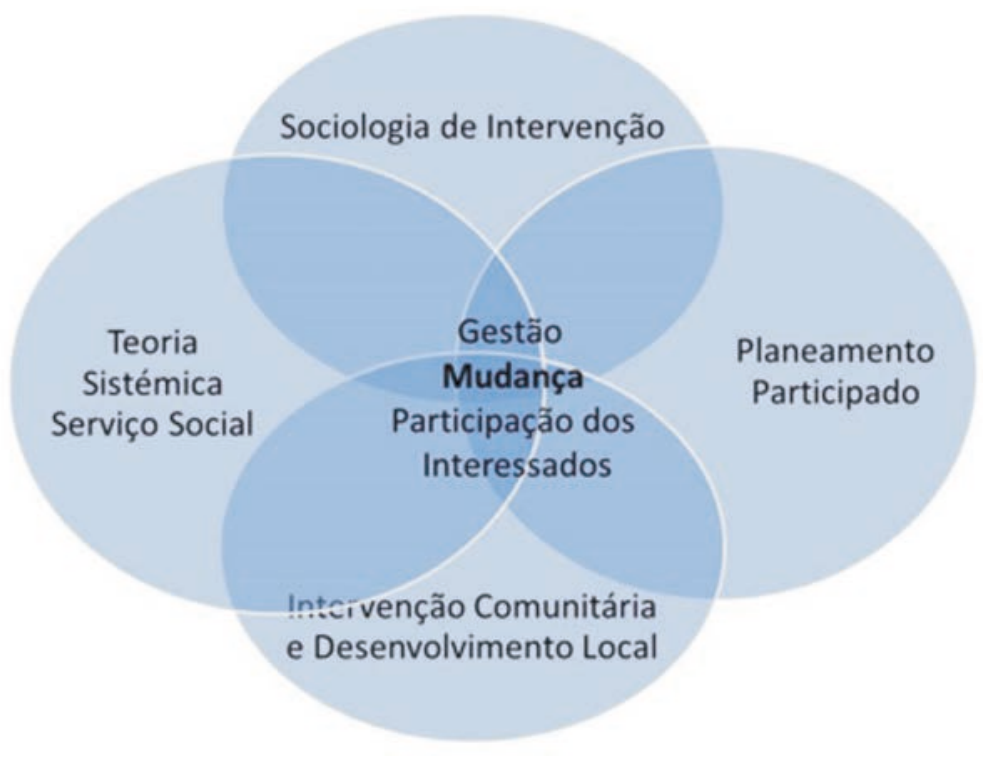

Figura 3 Bases da metodologia de intervenção Fonte: Fernandes (2017).

A figura 3 sintetiza as influências teóricas em que se baseou o desenvolvimento da intervenção. Como elemento comum a todas as áreas disciplinares identificadas surge a gestão da participação dos processos de mudança com todos os interessados ou parceiros (Guerra, 2006, p. 120).

Foi assim possível delinear a metodologia de acompanhamento, monitorização e gestão temporal do programa de execução para suporte aos planos de intervenção urbanística que se sintetiza na tabela 1.

Como resultado desta fase de ensaio foram ainda identificadas algumas medidas de intervenção imediata com o objetivo de prevenir a degradação e apropriação indevida e ou marginal dos fogos, aliás tendência detetada no decurso de todo o processo em todas as AUGI delimitadas. 
Tabela 1 Faseamento da ação

\begin{tabular}{|c|c|c|}
\hline Fase & Ações & Objetivo \\
\hline Exploratória & $\begin{array}{l}\text { Contacto com as organizações } \\
\text { locais }\end{array}$ & $\begin{array}{l}\text { - Caracterizar de dinâmicas sociais, } \\
\text { necessidades, carências e problemas } \\
\text { e sua distribuição no território; } \\
\text { - Identificar situações de } \\
\text { vulnerabilidade social em conjunto } \\
\text { com parceiros; } \\
\text { - Dinamizar de comissões conjuntas } \\
\text { onde ainda não estejam implantadas. }\end{array}$ \\
\hline $\begin{array}{l}\text { Conceção de instrumentos de recolha } \\
\text { de informação }\end{array}$ & $\begin{array}{l}\text { Elaboração dos guiões e } \\
\text { ajustamento das bases de } \\
\text { dados existentes e criação de } \\
\text { uma nova BD }\end{array}$ & $\begin{array}{l}\text { - Preparar a recolha de informação } \\
\text { sobre condições de habitabilidade e } \\
\text { sobre os agregados residentes. }\end{array}$ \\
\hline $\begin{array}{l}\text { Recolha de informação social sobre } \\
\text { os agregados residentes }\end{array}$ & $\begin{array}{l}\text { Trabalho c/ as organizações } \\
\text { locais }\end{array}$ & $\begin{array}{l}\text { - Elaborar listagem e prioridades para } \\
\text { a programação de visitas aos fogos. }\end{array}$ \\
\hline Organização de Equipas de visita & $\begin{array}{l}\text { Programação e realização } \\
\text { de visitas }\end{array}$ & $\begin{array}{l}\text { - Diagnosticar as situações e definir } \\
\text { respostas-tipo. }\end{array}$ \\
\hline $\begin{array}{l}\text { Articulação da intervenção social } \\
\text { direta com os serviços responsáveis }\end{array}$ & Reunião com serviços & $\begin{array}{l}\text { - Articular trabalho em rede com } \\
\text { parceiros e serviços-chave; } \\
\text { - Apresentar os resultados e } \\
\text { conclusões do diagnóstico; } \\
\text { - Definir critérios e prioridades de } \\
\text { atuação conjunta. }\end{array}$ \\
\hline $\begin{array}{l}\text { Programação das intervenções } \\
\text { a nível habitacional e social }\end{array}$ & $\begin{array}{l}\text { Programação de reuniões, } \\
\text { análise de situações; } \\
\text { Definição de prioridades, } \\
\text { respostas e recursos }\end{array}$ & $\begin{array}{l}\text { - Encaminhar e acompanhar } \\
\text { situações; } \\
\text { - Definir quadro de prioridades } \\
\text { articulado com planos urbanos e } \\
\text { processos de desocupação e } \\
\text { demolição. }\end{array}$ \\
\hline $\begin{array}{l}\text { Definição de um programa de ação } \\
\text { conjunta para a regeneração social } \\
\text { da zona }\end{array}$ & $\begin{array}{l}\text { Elaboração de programa } \\
\text { complementar }\end{array}$ & $\begin{array}{l}\text { Participar na programação de } \\
\text { atividades e elaborar plano de ação } \\
\text { local. }\end{array}$ \\
\hline
\end{tabular}

Fonte: Câmara Municipal de Lisboa (2016b).

\section{Uma experiência de planeamento participado}

Participação dos mediadores locais num processo de Planeamento Urbano da Área de Reabilitação Urbana (ARU) de St. ${ }^{a}$ Clara

O processo de delimitação da Área de Reabilitação Urbana de Santa Clara (ARU-Santa Clara) teve como intenção promover a integração e articulação de vários contextos urbanos, alguns ainda de cariz rural, com bastante relevância paisagística e patrimonial, da Coroa Norte da cidade e que incluem grande parte das AUGI de Lisboa. Esta operação constituiu uma oportunidade para uma primeira experiência de Planeamento Participado. 
Antes, no entanto, para nos situarmos é de referir que o Regime Jurídico de Reabilitação Urbana, Lei n. ${ }^{\circ}$ 32/2012, de 14 de agosto, veio estabelecer medidas que visam agilizar e dinamizar a reabilitação urbana.

A legislação define ARU como sendo a

área territorialmente delimitada que, em virtude da insuficiência, degradação ou obsolescência dos edifícios, das infraestruturas, dos equipamentos de utilização coletiva e dos espaços urbanos e verdes de utilização coletiva, designadamente no que se refere às suas condições de uso, solidez, segurança, estética ou salubridade, justifique uma intervenção integrada, através de uma Operação de Reabilitação Urbana aprovada em instrumento próprio ou em plano de pormenor de reabilitação urbana. (Lei n. ${ }^{\circ} 32 / 2012$, Preâmbulo) ${ }^{2}$

Para dar início ao processo realizou-se uma primeira visita ao terreno com uma equipa alargada de vários serviços camarários. Era preciso fixar um "retrato do território" que permitisse a partilha de informação, a negociação e o trabalho em parceria entre vários atores locais e serviços municipais.

Esta visita permitiu compreender a complexidade do território, desmontar alguns estereótipos e definir referências partilhadas sobre uma Área que vive um notório processo de estigmatização. Concluiu-se que seria oportuno promover a participação de, pelo menos, os representantes das organizações locais através da aplicação de métodos participativos.

\section{A elaboração de um diagnóstico participado}

Assim, definiram-se dois momentos principais de consulta, através da organização de focus groups (University of Kansas, 2014): 14 e 17 de março de 2016. Efetuou-se a seleção de um conjunto representativo de participantes pertencentes ou sugeridos por organizações e parceiros locais de cada zona identificada previamente, a quem se mandou convite: AUGI, Núcleo Histórico, Bairro Social e Promoção Imobiliária (figura 4).

A metodologia de focus groups foi escolhida por 4 motivos principais:

1. Esta metodologia permitia a formação de pequenos grupos e a discussão de pontos de vista com participantes muito diversos em termos culturais, sociais, habitacionais que enriqueceram o debate e as conclusões;

2. Existia uma relação consolidada com os responsáveis das principais organizações e parceiros locais por via do trabalho nas AUGI, Grupos Comunitários e Comissão Social de Freguesia, que permitia mobilizar rapidamente os seus representantes; 


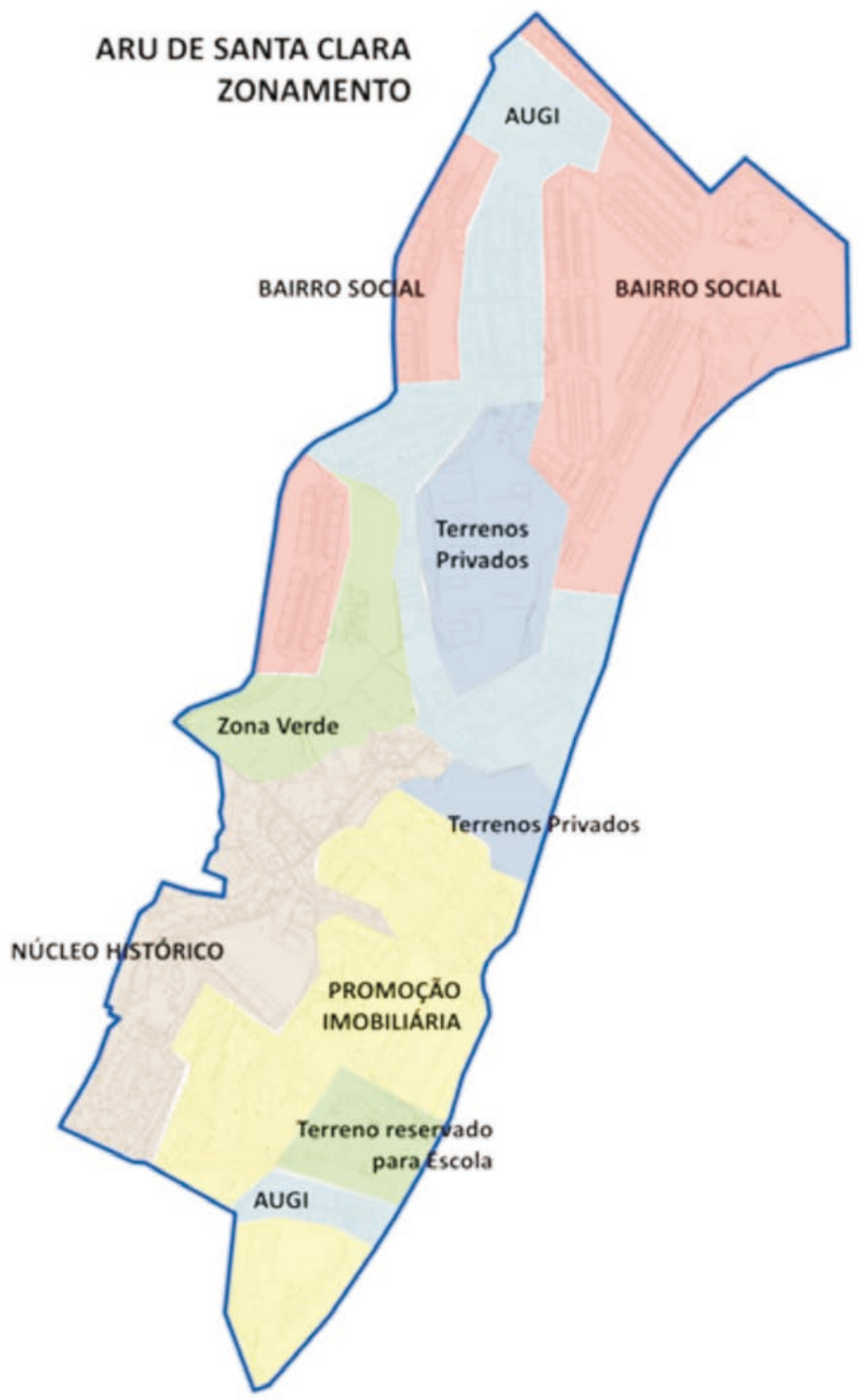

Figura 4 Tipologia de ocupação

Fonte: Câmara Municipal de Lisboa (2016a). 
3. A necessidade de "aproveitar" as relações estabelecidas e as dinâmicas de participação para um processo de diagnóstico, envolvimento e intervenção;

4. Metodologia que permite lançar as bases para uma melhor e mais equilibrada apropriação do território.

Em termos de dinamização das sessões contou-se com um mediador e um relator para cada grupo de 8 a 12 pessoas escolhidas em estreita colaboração com os serviços da CML que intervêm na zona com maior frequência.

As sessões tiveram uma duração de cerca de $2 \mathrm{~h} 30$ a 3 horas e tiveram como principais pontos, o que se designou como "desafios":

1. ${ }^{\circ}$ Desafio: Como descrevo este bairro (centrado numa das zonas identificadas e em todas a ARU)? O que o carateriza? O que os outros dizem sobre esta área? Ideias para contornar esta questão?;

2. ${ }^{\circ}$ Desafio: Passado - Como era este lugar? Presente - O que encontro hoje aqui? Futuro - O que espero que venha a acontecer?;

3. ${ }^{\circ}$ Desafio: Elaborar uma análise SWOT: pontos fortes e fracos, oportunidades e ameaças;

4. ${ }^{\circ}$ Desafio: Se eu fosse Presidente da CML, o que mandava fazer já amanhã?

As duas primeiras sessões, realizaram-se nas instalações da Câmara Municipal de Lisboa e tiveram a participação de 8 grupos. Os grupos analisaram e diagnosticaram situações e problemas que, na maior parte dos casos, foram georreferenciados para se perceber as dinâmicas sócio territoriais.

Verificou-se, no entanto, após as duas primeiras sessões, que havia setores da população que se encontravam sub-representados. Realizou-se mais uma sessão num equipamento situado num Bairro Municipal onde se tinham registado incidentes, de alguma gravidade, entre grupos rivais da comunidade cigana, o que tinha impedido a participação desses residentes.

Esta situação permitiu-nos perceber a origem da estigmatização e dos conflitos da zona. Em 2001, no âmbito do Plano Especial de Realojamento (PER), foram realojadas, sob escolta policial, famílias ciganas oriundas do Vale do Forno que já tinham rivalidades anteriores com famílias da zona. Este facto, a par do mau desenho e da má gestão urbana, potenciaram um ambiente de litígio e insegurança permanentes.

Em complemento a estas sessões organizaram-se outras destinadas a 3 turmas do $1 .^{\circ}$ Ciclo do Ensino Básico, uma por cada escola, no total de 3 Escolas Básicas do 1 . $^{\circ}$ Ciclo locais. Fizeram-se visitas ao território com o pastor da Ameixoeira que mantém um dos últimos rebanhos da zona. Fez-se igualmente uma visita com o responsável do Gabinete de Projetos de Espaços Verdes da CML ao Parque da Ameixoeira, Parque Periférico, em execução. 
Tabela 2 Organizações representadas

\begin{tabular}{llr}
\hline & Tipo de organizações representadas & N.o de participantes \\
\hline 1 & IPSS & 6 \\
2 & Associações locais & 4 \\
3 & Juntas de Freguesia & 3 \\
4 & Serviços e empresas municipais & 10 \\
5 & Empresas locais & 2 \\
6 & Associações ambientais & 1 \\
7 & Saúde & 3 \\
8 & Educação/Escolas & 58 \\
9 & Mediadores locais & 3 \\
10 & SCML & 4 \\
11 & Comissões de administração conjunta AUGI & 8 \\
12 & Associações de pais & 3 \\
13 & Universidade - investigadores & 1 \\
14 & Moradores & 9 \\
& Total & 115 \\
\hline
\end{tabular}

Fonte: Câmara Municipal de Lisboa (2016a).

A última sessão organizou-se na Academia de Santa Cecília, no dia 16 de maio e teve como objetivo a "devolução" de conclusões e propostas resultantes das sessões anteriores. Todo este processo foi objeto de avaliação através de formulário de aplicação direta e por via email (survey-monkey).

No processo de diagnóstico procedeu-se também à análise comparativa entre os dados dos Censos de 2001 e 2011 e concluiu-se em relação às zonas identificadas no mapa anterior, (figura 4):

AUGI - os antigos proprietários e construtores das AUGI estão a ser substituídos por arrendatários mais jovens com situações sociais e laborais precárias; o "padrão" da Quinta do Olival repete-se;

Núcleo Histórico - Zona em processo de envelhecimento e esvaziamento;

Bairros Sociais - Elevado número de residentes em situação de vulnerabilidade social e dependentes do apoio institucional; no entanto, cerca de $1 / 3$ da população residente é proprietária da própria casa (zona habitação baixos custos);

Promoção Imobiliária - Houve um crescimento dos residentes da zona apesar da crise imobiliária;

Os resultados dos focus groups (Rabiee, 2004) são, de modo muito sintético, apresentados na tabela 3 . 
Tabela 3 Síntese das propostas por áreas

Imagem urbana: desenho e gestão urbano, perceção do exterior, etc.

Sob o signo da insegurança - Incidência do tema ao longo da conversa

As fronteiras invisíveis entre zonas - georreferenciação mpa diagnóstico

Círculo vicioso da exclusão: insegurança cria isolamento e marginalização no território; isolamento cria insegurança e marginalidade e falta de circulação interna à zona o que cria atomização espacial e social

Quebrar o isolamento e melhorar a comunicação da imagem para o exterior

Edificado: ocupação, uso, qualidade, valorização, manutenção etc.

Triângulo estratégico: ordenar, requalificar e reabilitar

Desenvolver novas estratégias para gestão da habitação social e das lojas municipais

Espaço público: barreiras, mobiliário, uso, sinalética, leitura, etc.

Triângulo estratégico: ordenar, requalificar e reabilitar

Mobilidade e inter-conetividade interna

Espaço público é preciso, já

Uma zona à procura de um centro

Resgatar a memórias das quintas e do campo

"Emendar" erros desenho urbano e barreiras - georreferenciado mapa

Aumentar acessibilidade e mobilidade pedonal segura

Políticas sociais: habitação, educação, coesão social, inclusão, saúde, segurança, etc.

Equipamentos âncora em falta: centro de saúde, esquadra, metro

Atividade económica e emprego precisa-se

Promover coesão social e a comunicação e colaboração entre grupos e culturas

Promover inclusão, participação e o trabalho em parceria

Intensificar projetos de promoção competências e empowerment

Fonte: Câmara Municipal de Lisboa (2016a).

Além desta síntese, há ainda a salientar dois aspetos importantes que, à partida, não eram expectáveis. Em primeiro lugar, numa análise comparativa do número de agregados apoiados pela Ação Social da Santa Casa da Misericórdia de Lisboa, verificou-se que as AUGI tinham maior percentagem de situações de vulnerabilidade quando, à partida, se apontavam os Bairros Sociais como zonas prioritárias.

O segundo aspeto: no levantamento das atividades económicas concluiu-se que houve um efeito indutor da estação de Metro da Ameixoeira (finalizada em 2009) na atração de empresas e emprego àquela zona.

Tendo em conta este diagnóstico que visa dar resposta às grandes questões apresentadas na tabela anterior, a intervenção municipal em curso definiu como grandes objetivos para a Área de Reabilitação Urbana (ARU) de St. ${ }^{a}$ Clara: 
a "vertebração/legibilidade urbana e a promoção da coesão sócio territorial" (Câmara Municipal de Lisboa, 2016a) contemplando, em simultâneo, a intervenção urbana à intervenção social.

\section{Processos de gestão da mudança com a participação dos residentes}

Das Áreas Urbanas de Génese Ilegal onde a DRAUGI intervém, o Bairro das Galinheiras é, sem dúvida, o mais antigo e o maior. Apresenta uma diversidade urbana e social rica e complexa.

Para dar início ao processo de reconversão deste Bairro, à semelhança do que aconteceu noutras intervenções, contou-se com os parceiros locais, sobretudo os mais diretamente envolvidos nesta zona. Apostou-se em metodologias de trabalho participativo complementares à articulação que já se desenvolve em várias instâncias locais: Comissão Social de Freguesia; Comissões de Administração Conjunta e Grupo Comunitário e ainda a colaboração com outros parceiros exteriores a estes foros.

Para arranque deste processo organizou-se o projeto "Fotos-Vozes" (Hunger through my lens, 2014) que tem como objetivo conhecer o Bairro das Galinheiras através do olhar dos seus moradores.

Trata-se de uma metodologia simples que consiste na organização de pequenos grupos de moradores ( 5 a 12 pessoas) equipados com câmara ou telemóvel, que fazem percursos pelo bairro para tirar fotografias às quais acrescentam posteriormente um comentário. Tanto as fotografias como os comentários serão subjetivos e versam sobre qualquer assunto ou tema que diga respeito a quem e a como se vive no Bairro das Galinheiras.

Foram organizados vários percursos pelo Bairro conforme figura 5, numa combinação entre a metodologia foto-vozes e o mapeamento da comunidade (Pathways through Participation, 2010).

Na organização e dinamização desses grupos contámos com a colaboração de um parceiro/organização mentora por percurso, que colaborou com a equipa nos seguintes aspetos: contacto com os participantes, explicação/formação, registo, análise e reflexão sobre os resultados, fotografias e comentários recolhidos e selecionados. No final pretende-se organizar uma exposição com o trabalho efetuado.

Foram abrangidos neste processo grupos de moradores representativos da diversidade social, etária, étnica, de unidade de vizinhança assim como, na sua "utilização" e pertença a organizações e instituições locais: escola, centro de dia, associações, clubes, etc. 


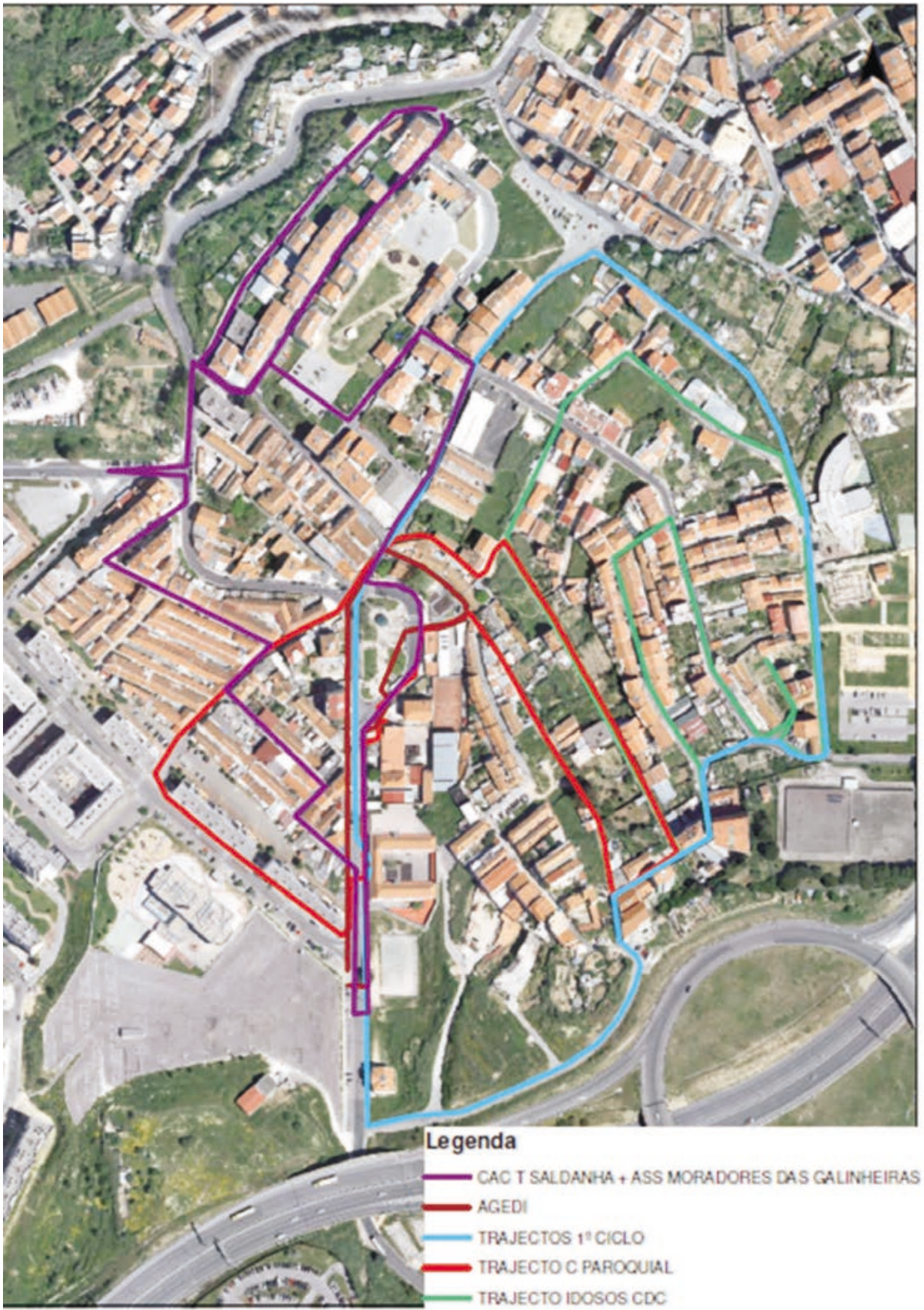

Figura 5 Mapa dos trajetos

Fonte: Câmara Municipal de Lisboa (2016c). 
Como conclusões deste trabalho, ainda em curso, temos: elevado número de terrenos vagos que constituem um problema devido ao mau uso e à degradação; ocupação indevida e marginal de casas vagas ou devolutas; espaço público degradado; equipamentos coletivos com falta de manutenção; situações de marginalidade e tráfico de droga.

A par deste trabalho deu-se início às visitas técnicas aos imóveis que não são passíveis de legalização e onde se verificam fenómenos já registados anteriormente no ensaio da metodologia. Das 74 habitações visitadas, $5 \%$ do total de alojamentos da zona delimitada, registou-se: ocupação indevida, coabitação entre agregados para poderem suportar a renda, elevado número de agregados imigrantes, 55\% dos agregados; arrendamento como complemento de reforma para proprietários e herdeiros; identificação de núcleos habitacionais sem quaisquer condições de habitabilidade.

Apesar de já terem decorrido 7 anos e os dados já não refletirem o que nos era dado a observar no terreno efetuou-se, ainda assim, a análise comparativa dos Censos 2001-2011 de onde se concluiu que houve aumento: de 10\% de Alojamentos vagos; 5,5 \% Famílias com residentes $+65 ; 6 \%$ residentes com +65 anos. Mais uma vez se confirma o padrão inicial da AUGI da Qt. ${ }^{a}$ do Olival.

Tentando ir um pouco mais longe na análise, tratámos os dados relativos à população escolar da zona, Escola Básica $1{ }^{\circ}$ Ciclo e Jardim de Infância e mais 2 Estabelecimentos de Apoio à Infância - Creche e JI, relativamente à nacionalidade das crianças e dos seus pais, tendo constatado o que se apresenta nas figuras 6 e 7 .

Verifica-se assim que os alunos de nacionalidade estrangeira representam $23 \%$ do total de alunos do $1 .^{\circ}$ Ciclo (6-10 anos) (figura 6). Assim, é expectável que os pais dos alunos de nacionalidade estrangeira do $1 .^{\circ}$ ciclo representem um valor próximo dos $23 \%$. No que diz respeito aos pais das crianças de idades compreendidas entre os 4 meses e os 5 anos dos estabelecimentos da zona, os dados revelam que, em média, 44,5\% dos pais têm nacionalidade estrangeira (figura 7). Neste sentido, é provável que, no prazo de 3 a 5 anos, possa ocorrer um aumento de filhos de pais imigrantes a frequentar o $1 .^{\circ}$ ciclo na Escola das Galinheiras em consequência da transição das crianças do ensino pré-escolar para o $1 .^{\circ}$ Ciclo. Sabemos que, por norma, as crianças destes estabelecimentos acabam por vir a frequentar esta escola. 


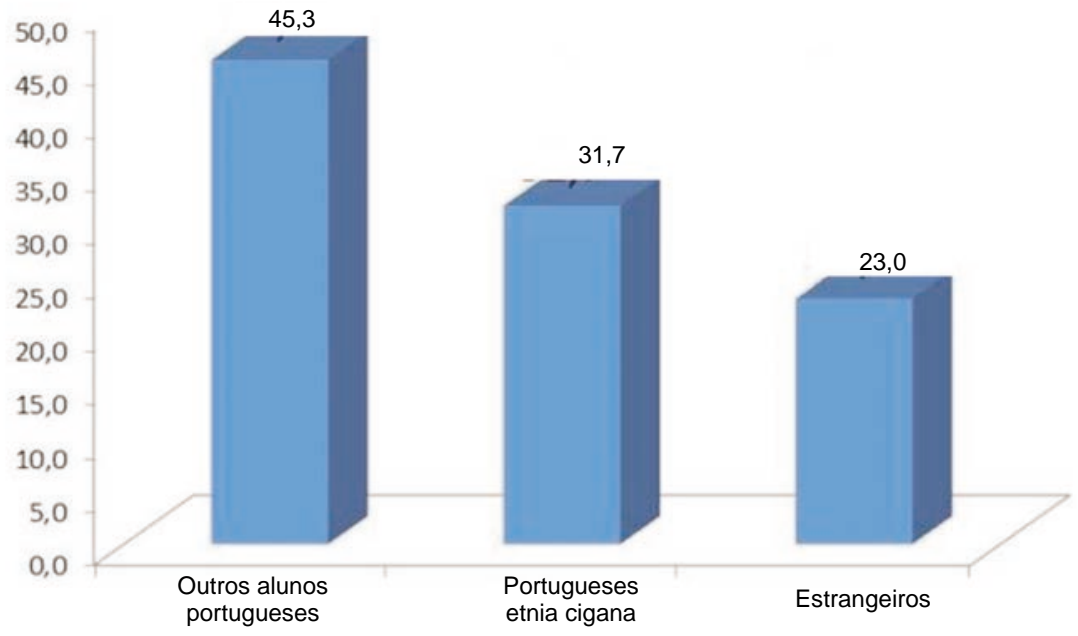

Figura 6 Nacionalidade dos alunos do 1. Ciclo - EB1 Galinheiras

Fonte: EB1 Maria da Luz de Deus Ramos (2017, abril).

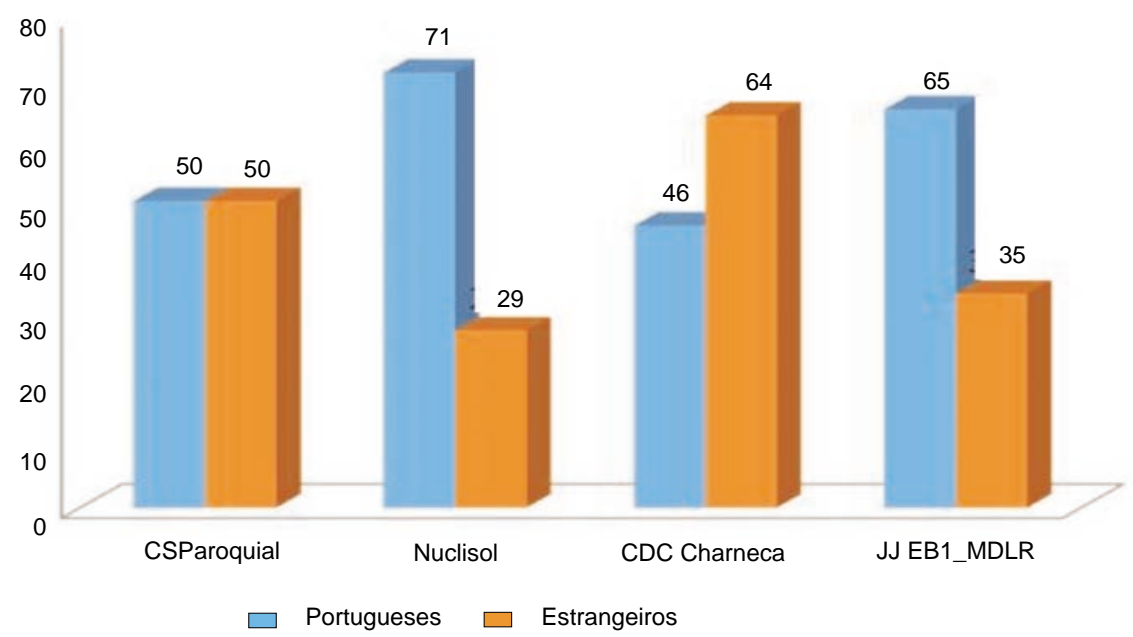

Figura 7 Estabelecimentos apoio à infância Galinheiras — Nacionalidade pais crianças (4 meses-5 anos) (\%)

Fonte: Organizações locais de Apoio à Infância (2017)..$^{(*)}$

(*) Centro Social e Paroquial das Galinheiras; Nuclisol; Centro de Desenvolvimento Social das Charneca SCML; EB1 M. 므 da Luz Deus Ramos — Jardim de Infância. 


\section{Reflexão crítica}

O trabalho encontra-se a decorrer. Por agora, é possível apontar para alguns tipos de ação a desenvolver: articulação com outros serviços da CML para a elaboração de Plano de Ação Local; apresentação das conclusões e resultados aos parceiros; exposição e apresentação pública de fotos e comentários no Projeto "Foto-Vozes"; testar ferramentas de participação online; definir modelos de avaliação.

Para um trabalho de curto prazo, face a processos de mudança longos e complexos, permite-nos apenas apresentar algumas conclusões mais "superficiais" e muitas interrogações relativamente a aspetos mais "percetíveis" de forma direta neste trabalho de terreno.

Os limites da cidade têm ou não sido também os limites da inclusão e da exclusão social territorial? As AUGI apresentam dimensão metropolitana: trata-se de um território a norte de Lisboa que vai do concelho de Cascais ao concelho de Vila Franca de Xira (Gonçalves et al., 2010). Como se criaram as "traseiras" da cidade de Lisboa nestes concelhos suburbanos? Qual a dimensão adequada da intervenção: local, regional ou nacional?

É um facto, que um local que serviu como "entreposto de mobilidade" (Costa, 1985) para os migrantes internos da geração dos "construtores" das AUGI, é agora também de ponto de partida para uma população imigrante.

Aliás, é notória a cultura de clandestinidade a todos os níveis: desde o processo de arrendamento, à contratação dos trabalhadores no comércio local, às situações de residência dos imigrantes. Promover a participação e o "empowerment" para comunidades silenciosas e "clandestinas" é um desafio.

Como gerir e planear a intervenção de forma sustentada e previsível é igualmente um desafio e é difícil avaliar se geramos mudança ou gerimos a mudança.

As dinâmicas sociais ultrapassam os limites administrativos dos concelhos, regiões, países e as estratégias de nível local bem como, as políticas sociais territoriais apresentarem as suas limitações.

Concertar uma intervenção a nível de grandes organizações que intervêm na cidade e dar-lhe um caráter integrado, sustentado e em parceria é um outro nível que a intervenção participada e de micro nível não resolve. Tal como não resolve a concertação de culturas organizacionais e profissionais dominantes: burocratizadas, hierarquizadas, autocentradas.

A gestão deste tipo de processos apresenta assim alguns riscos a que é necessário estar atento para a definição de um compromisso entre a participação e o planeamento de médio/longo prazo da cidade. Logo, é necessário salvaguardar que os processos de participação tenham eficácia a nível dos resultados, que haja 
a feedback e gestão adequada da comunicação e das expectativas de todos os interessados sob pena destas experiências se tornarem episódicas e demagógicas.

A deontologia e a éticos da intervenção é igualmente fundamental: desde a gestão da informação entre parceiros e serviços, passando pelo direito à imagem até à organização de bases de dados, Como se partilha e quem acede a que informação? Para quê? Quando? Estas são questões que se mantêm ao longo de toda a intervenção e às quais é necessário estar atento.

Por último, fica-nos como linha de orientação e reflexão, retirada do programa das Nações Unidas para os assentamentos humanos, UN-Habitat (2015), Diretrizes internacionais para planejamento urbano e territorial:

O planejamento urbano e territorial representa um componente fundamental do paradigma renovado de administração urbana, que promove a democracia local, a participação e a inclusão, a transparência e a responsabilidade, com vista a garantir a urbanização sustentável e a qualidade espacial. (UN-Habitat, 2015, p. 8)

\section{Notas}

1 O Programa BIP/ZIP tem como objetivo apoiar parcerias locais na identificação e gestão de respostas às carências nos bairros ou zonas de intervenção prioritária.

2 A Delimitação de uma Área de Reabilitação Urbana, [alínea a) e b) do artigo 2. ${ }^{\circ}$ do RJRU], traduz-se em benefícios fiscais no imposto municipal sobre imóveis (IMI) e imposto municipal de transmissões onerosas de imóveis (IMT).

Por decisão pessoal, o autor do texto escreve segundo o Novo Acordo Ortográfico.

\section{Referências}

Câmara Municipal de Lisboa. (2013). Regulamento municipal para reconversão urbanística das Áreas Urbanas de Génese Ilegal. Diário da República II Série. N. 128 (13-07-05), 21256-21259.

Câmara Municipal de Lisboa. (2016a). Área de reabilitação urbana de St. ${ }^{a}$ Clara (Relatório diagnóstico). Lisboa: CML.

Câmara Municipal de Lisboa. (2016b). Proposta de plano de pormenor da Quinta do Olival e Marquês de Abrantes. Lisboa: CML.

Câmara Municipal de Lisboa. (2016c). Proposta projeto foto-vozes. Lisboa: CML.

Costa, A. F. (1985). Espaços urbanos e espaços rurais: Um xadrez em dois tabuleiros. Análise Social, XXI (87-88-89), 735-756. Retrieved from http://analisesocial.ics.ul.pt/documentos/1223478825H5hMF0jk9Em99KY7.pdf Decreto Lei n. ${ }^{\circ}$ 32/2012. (2012). Procede à primeira alteração ao Decreto-Lei n. ${ }^{\circ}$ 307/2009, de 
23 de outubro, que estabelece o regime jurídico da reabilitação urbana, e à $54 .^{a}$ alteração ao Código Civil, aprovando medidas destinadas a agilizar e a dinamizar a reabilitação urbana. Diário da República I Série. N. ${ }^{\circ}$ 157/2012 (12-08-14), 4452-4483.

Decreto Lei n. ${ }^{\circ}$ 91/95. (1995). Processo de reconversão das áreas urbanas de génese ilegal. Diário da República I Série. N. ${ }^{\circ}$ 203/1995 (95-09-02), 5542- 5550.

Fernandes, A. (2017). Planear a cidade com as pessoas. Comunicação apresentada no Encontro APS - Sociologia e Intervenção Local, Lisboa, Portugal.

Ferreira, A. F., et al. (1985). Perfil social e estratégias do "clandestino": Estudo sociológico da habitação clandestina na Área Metropolitana de Lisboa. Lisboa: CES.

Friedman, J. (2011). Insurgencies: Essays in planning theory. New York: Routledge.

Gonçalves, J., et al. (2010). Do ilegal ao formal: Percursos para a reconversão urbana das áreas urbanas de génese ilegal em Lisboa. In L. Bogus, et al. (Orgs.), Da irregularidade fundiária urbana à regularização: Análise comparativa Portugal - Brasil (pp. 161-192). São Paulo: EDUC.

Guerra, I. C. (2006). Fundamentos e processo de uma sociologia da acção. O planeamento em ciências sociais. Lisboa: Principia.

Horelli, L., et al. (2013). New approaches to urban planning. Insights from participatory communities. Finland: Alto University.

Hunger through my lens. Photovoice case study and toolkit. (s.d). Retrieved from http:/ / hungerthroughmylens.org/resources/photovoice-kit/

Krueger, R., \& Casey, M. A. (2000). Focus groups: A practical guide for applied research. Thousand Oaks: Sage Publications.

Pane, M. (2002). Teoria do trabalho social moderno. Coimbra: Quarteto Editora.

Pathways through Participation. (Org.) (2010). Using participatory mapping to explore participation in three communities (Report). Retrieved from http:/ / pathwaysthroughparticipation.org.uk/

Rabiee, F. (2004). Focus-group interview and data analysis. Proceedings of the Nutrition Society, 63(4), 655-660. Retrieved from https://www.ncbi.nlm.nih.gov/pubmed/15831139

UNECE., \& FIG. (Orgs.) (2015). Formalizing the informal: Challenges and opportunities of informal settlements in South-East Europe (Report) [PDF]. Retrieved from https://www.unece.org/fileadmin/DAM/hlm/documents/Publications/Formali zing_the_Informal_Challenges_and_Opportunities_of_Informal_Settlements_in_S outh-East_Europe.pdf

UN-Habitat. (2015). Diretrizes internacionais para planejamento urbano e territorial. Retrieved from https://unhabitat.org/books/diretrizes-internacionais-para-planejamento-urbano-eterritorial/

University of Kansas. (2014). Implementing photovoice in your community. Retrieved from http://ctb.ku.edu/en/table-of-contents/assessment/assessing-community-needsand-resources/photovoice/main

Wang, C.C. (2006). Youth participation in photovoice as a strategy for community change. Journal of Community Practice, 14(1/2), 147-161. Retrieved from 
http:/ / phdresearchdesignandimplementation.yolasite.com/resources/photovoice $\% 20$ strategy $\% 20$ for $\% 20$ community $\% 20$ change.pdf

Zanfi, F. (2013). The città abusiva in contemporary Southern Italy: Illegal building and prospects for change. Urban Studies, 50(16), 3428-3445. Retrieved from http://journals.sagepub.com/doi/pdf/10.1177/0042098013484542

Álvaro Fernandes. Câmara Municipal de Lisboa, Departamento de Planeamento (DP), Divisão de Reconversão das Áreas Urbanas de Génese Ilegal (DRAUGI).

Data de submissão: 16/06/2017 | Data de aceitação: 13/10/20173 